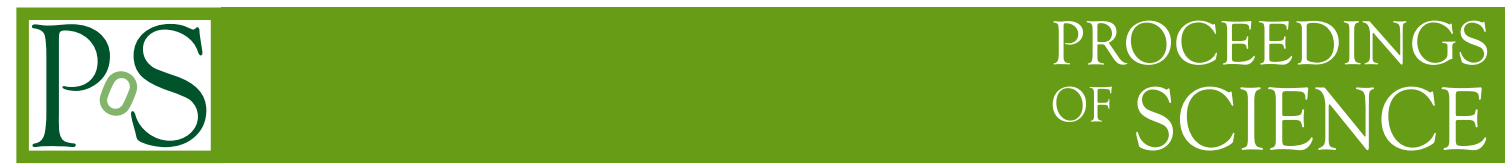

\title{
Loop Quantum Gravity
}

\section{Carlo Rovelli*}

Université Aix-Marseille

E-mail: rovelli@cpt.univ-mrs.fr

I give a general overview of the developments in Loop Quantum Gravity and I describe a recent idea for a possible novel window of observation of quantum gravitational phenomena: Planck stars.

Frontiers of Fundamental Physics 14 - FFP14,

15-18 July 2014

Aix Marseille University (AMU) Saint-Charles Campus, Marseille

* Speaker. 